\title{
Bacterial Growth Inhibitory Effects of Calotropis procera's Latex, Leaves and Roots Extracts
}

\author{
Marco Baluhya and Charles O Joseph* \\ Department of Botany, College of Natural and Applied Sciences, University of Dar es Salaam, \\ P. O. Box 35060, Dar es Salaam, Tanzania. \\ *Correspondence: E-mail: jnyengo@yahoo.co.uk; jcharles@udsm.ac.tz \\ Received 1 Feb 2021, Revised 28 Apr 2021, Accepted 30 Apr 2021, Published May 2021 \\ DOI: https://dx.doi.org/10.4314/tjs.v47i2.20
}

\begin{abstract}
This study was conducted to evaluate in vitro antibacterial potential of water and ethanolic extracts from Calotropis procera roots, leaves and latex. The growth inhibitory effects of the extracts were tested against Escherichia coli using disc diffusion method. Amoxicillin was used as positive control, whereas ethanol and distilled water were used as negative controls. Results showed that water extracts from root, latex and leaves had $3.27 \pm 0.14,3.1 \pm 0.21$ and $2.38 \pm 0.24 \mathrm{~cm}$ of maximum inhibition zones, while the ethanolic extracts showed $2.91 \pm 0.19,3.02 \pm 0.16$ and 0.84 $\pm 0.31 \mathrm{~cm}$, respectively of maximum inhibition zones. The positive control; amoxicillin had $3.56 \pm$ $0.09 \mathrm{~cm}$ of maximum inhibition zone. Post hoc tests revealed that roots, latex and conventional amoxicillin were equally effective in inhibiting $E$. coli growth. It further revealed that water extracts exhibited more growth inhibitory effects than ethanol extracts. No significant variations were observed on the E. coli growth inhibition due to the locations from where $C$. procera were collected. Generally, results indicated that $C$. procera inhibited the growth of $E$. coli. Thus its uses for the development of traditional and complementary medicines and further investigation on its biological activity on other microbes are highly recommended.
\end{abstract}

Keywords: Antibacterial, Calotropis procera, Diameter of inhibition zone. Escherichia coli, Plant crude extract, Traditional medicine.

\section{Introduction}

Medicinal plants and their extracts have been the basis for medical treatments through most of human history and have always provided a foundation for modern pharmaceutical compounds (Yuan et al. 2020). According to the WHO (2020), antibiotic resistance is rising to dangerously high levels in all parts of the world. The rise has been associated with ecological, evolutionary and environmental factors (Johan et al. 2018). Therefore, investment in research and development of new antibiotics, vaccines, diagnostics and identification of effective and less toxic new bioactive plant extracts from the medicinal plants is overemphasized. Plant extracts represent rich sources of antimicrobial agents with a low level of toxicity, a broad spectrum and sufficiently good pharmacokinetics to be clinically useful without chemical modifications (Mensah et al. 2019). Plants contain various bioactive secondary metabolites such as terpenoids, flavonoids, saponins, steroids and cardiac glycosides (Morsy et al. 2016) which exhibit diverse biological activities such as cytotoxic, anticancerous, anti-inflammatory, analgesic, anti-nociceptive and hepatoprotective activities (Kumar et al. 2010). The anti-inflammatory, anti-allergic, immunomodulatory, secretory-

648 
modulating, and metabolic regulatory actions of the traditional medicines have been associated with the restoration of normal molecular and cellular functions through DNA transcriptional regulation (Miyata 2007).

Calotropis procera is one of the medicinal plant species that is adapted to the semi-arid and disturbed environment (Heuzé et al. 2016). The latex of $C$. procera extract is easily available and is used in medicines for treatment of many diseases. It is used as wound healing agent, anti-diarrheal, anti-inflammatory and anti-rheumatism agent (Oudhia 2001). It is also used by traditional medicine practitioners in communities for the treatment of ring worms (Kuta 2008). The plant is also known for its toxic properties that include dermatitis, iridocyclites and acts like a poison and produces lethal effects (Varahalarao and Chandrashekar 2010). Although various parts of $C$. procera have been extensively used by local people in most parts in Tanzania for the treatments of skin diseases, stomach pain, hernia, ulcers, abdomen pain, diarrhoea, pneumonia and respiratory illness (personal communication with herbal practitioners), little is known about its antimicrobial activities especially in Tanzania. Therefore, the aim of this study was to investigate the antibacterial activities of roots, leaves and latex extracts of Calotropis procera obtained from Shinyanga and Dares Salaam Regions. Information on $C$. procera is useful to identify its potential for development of traditional and complementary medicines for human health management.

\section{Materials and Methods Materials}

Leaves, roots and latex of $C$. procera plant were collected between March and May 2019 from Dares Salaam and Kahama District in Shinyanga. Plants identification was done at the Department of Botany, University of Dar es Salaam.

\section{Crude plant extracts}

Both the roots and leaves were washed thoroughly using distilled water to remove dust and any adhering soil and disinfected using sodium hypochlorite. The cleaned and disinfected, roots and leaves were oven dried at $40{ }^{\circ} \mathrm{C}$ for 48 hours then ground to powder. Latex was dried through a rotary heat shaker then ground into powder. For water extracts, $10 \mathrm{~g}$ of the powder of each plant part were mixed with $100 \mathrm{~mL}$ of distilled water then allowed to set in the conical flask for 24 hours with intermitted shaking after every 6 hours. After 24 hours the mixture was allowed to stand for 8 hours then filtered using Whatman paper. For ethanol extracts, $10 \mathrm{~g}$ powder from each plant part were mixed with $100 \mathrm{~mL}$ of ethanol $70 \%$ and kept on the rotary shaker at $100 \mathrm{rpm}$ overnight and then filtered using Whatman filter paper. Both water and ethanol extracts were evaporated to near dryness in rotary evaporator with constant stirring.

\section{Bacterial growth media preparation}

The Mueller Hinton Agar was prepared by dissolving $19 \mathrm{~g}$ of the solid media in distilled water to make a $500 \mathrm{~mL}$ of solution and adjusted to $\mathrm{pH}$ 6.7. The solution was then sterilized in an autoclave at $121{ }^{\circ} \mathrm{C}$ for 15 minutes, then cooled. After cooling, it was poured in clean and sterilized petri dishes and left to solidify.

\section{Preparation of disc}

The Whatman filter papers were cut using punch machine to form small round papers (discs). The discs were then raped in foil and sterilized using an autoclave at $121{ }^{\circ} \mathrm{C}$ for 15 min. After sterilization, while working in Laminar Air Flow Cabinet (LAFC) in sterile condition, the discs were placed in sterile petri dishes. Few drops of each extracts were used to impregnate each disc using micropipettes and allowed for few minutes to be absorbed. The discs were then allowed to dry for one minute. The average weight of disc after drying was $0.003833 \mathrm{~g}$. The weight of plant extracts used in each disc was calculated as the average weight of the disc after drying-average weight of the empty disc. This was equivalent to = $(0.003833-0.00274)=0.0010933 \mathrm{~g}$ 
Baluhya and Joseph - Bacterial growth inhibitory effects of Calotropis procera's latex ...

\section{Inoculation microorganism}

In the laminar flow cabinet, a sterile cotton swab was dipped into the standardized bacterial inoculum suspension, and then spread over the whole sterile surface of Mueller-Hinton agar petri dish (MHA; Becton-Dickinson, USA).

\section{Assessment of antibacterial activity}

One petri dish was subdivided into six parts; each part contained two discs impregnated with either leaves, root or latex extracts, amoxicillin (positive control) or water/ ethanol (negative control). Antibacterial activity was observed as a clear inhibition zone that created circular zone of inhibition around the discs (Figure 1). The diameter of the zone of inhibition was measured in centimeter using a ruler.
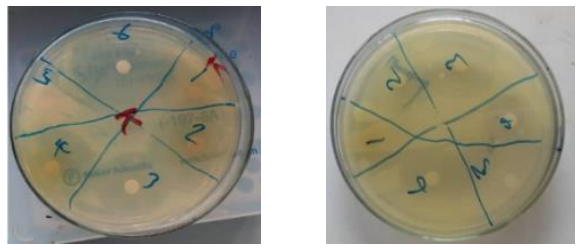

Figure 1: Representative samples showing inhibition zones.

\section{Statistical data analysis}

The variations of mean inhibition zones were analysed using Factorial ANOVA and turkey student $t$ test both in SAS 9.2 package. Plant parts (root, latex and leaves), solvent medium (water and ethanol) and environments (Kahama and Dar es Salaam) were the main factors/independent variables and diameter of growth of inhibition zone was a dependent variable.

\section{Results \\ Bacterial growth inhibition}

C. procera extracts were effective against Escherichia coli (Table 1). The diameters of zones of inhibition of $E$. coli growth depended on the solvent of extraction, plant part and the environment from where the plant was collected. The average diameters of zones of inhibition ranged between $0.82 \pm 0.38$ to $0.85 \pm$ $0.24 \mathrm{~cm}$ for leaf ethanol (LE), $2.35 \pm 0.22$ to $2.42 \pm 0.25$ for leaf water (LW), $2.88 \pm 0.13$ to $2.93 \pm 0.24$ for root ethanol $(\mathrm{RE})$ and $3.15 \pm$ 0.17 to $3.38 \pm 0.11 \mathrm{~cm}$ for root water $(\mathrm{RW})$ extracts from Dar es Salaam and Kahama Shinyanga respectively. The average diameters of zones of inhibition of $E$. coli growth for the latex ethanol $(\mathrm{LaE})$ extract was $3.02 \pm 0.16$ and latex water $(\mathrm{LaW})$ extract was $3.1 \pm 0.21 \mathrm{~cm}$. The least diameter of the growth inhibition zone was exhibited by leaves extracts using ethanol $(0.82 \pm 0.38$ and $0.85 \pm 0.24 \mathrm{~cm})$ and highest diameter of the growth inhibition zone was from root extracts $(3.15 \pm 0.17$ and $3.38 \pm$ 0.11) collected from Dar es Salaam and Shinyanga, respectively, while the latex extracts had $3.02 \pm 0.16 \mathrm{~cm}$ of inhibition zone. The average zone of inhibition showed by positive control, the amoxicillin was $3.56 \pm$ $0.09 \mathrm{~cm}$. This was equivalent to $69.8,13.22$ and $13.92 \%$ more effective than leaf, root and latex extracts respectively.

Table 1: Bacterial growth inhibition zone $(\mathrm{cm})$ from RW-root water, LW-leaf water, RE-root ethanol, LW- leaf water, LaW-latex water, LaE-latex ethanol and LE-for leaf ethanol extracts) $n=$ 6.

\begin{tabular}{llllllll}
\hline \multicolumn{7}{l}{ Bacterial growth inhibition zone (cm), Sample from Dar es Salaam } \\
\hline REP & LE & LW & RE & RW & LaE & LaW & Amoxicillin \\
\hline 1 & 0.60 & 2.20 & 2.80 & 3.00 & 3.00 & 3.40 & 3.50 \\
2 & 1.60 & 2.40 & 3.00 & 3.20 & 3.00 & 2.90 & 3.60 \\
3 & 0.90 & 2.70 & 3.10 & 3.10 & 2.90 & 3.20 & 3.40 \\
4 & 0.50 & 2.50 & 2.80 & 2.90 & 3.10 & 2.80 & 3.60 \\
5 & 0.80 & 2.00 & 2.70 & 3.30 & 2.80 & 3.00 & 3.70 \\
6 & 0.50 & 2.30 & 2.90 & 3.40 & 3.30 & 3.30 & 3.40 \\
M \pm SD & $\mathbf{0 . 8 2} \pm \mathbf{0 . 3 8}$ & $\mathbf{2 . 3 5} \pm \mathbf{0 . 2 2}$ & $\mathbf{2 . 8 8} \pm \mathbf{0 . 1 3}$ & $\mathbf{3 . 1 5} \pm \mathbf{0 . 1 7}$ & $\mathbf{3 . 0 2} \pm \mathbf{0 . 1 6}$ & $\mathbf{3 . 1} \pm \mathbf{0 . 2 1}$ & $\mathbf{3 . 5 3} \pm \mathbf{0 . 1 1}$ \\
\hline
\end{tabular}


Tanz. J. Sci. Vo. 47(2) 2021

Table 1 (Ctd)

\begin{tabular}{llllll}
\hline \multicolumn{7}{l}{ Bacterial growth inhibition zone(cm), Sample from Kahama } \\
\hline REP & LE & LW & RE & RW & Amoxicillin \\
\hline 1 & 0.80 & 2.10 & 2.50 & 3.30 & 3.60 \\
2 & 0.40 & 2.40 & 2.80 & 3.40 & 3.50 \\
3 & 1.00 & 2.20 & 3.00 & 3.50 & 3.60 \\
4 & 1.20 & 2.80 & 3.20 & 3.40 & 3.50 \\
5 & 0.90 & 2.30 & 2.90 & 3.50 & 3.70 \\
6 & 0.80 & 2.70 & 3.20 & 3.20 & 3.60 \\
$\mathrm{M} \pm$ SD & $0.85 \pm 0.24$ & $2.42 \pm 0.25$ & $2.93 \pm 0.24$ & $3.38 \pm 0.11$ & $3.58 \pm 0.07$ \\
\hline
\end{tabular}

Effects of solvent of extraction, plant part and environment on $C$. procera ability to inhibit $E$. coli growth

The average diameters of zones of inhibition of $E$. coli growth were significantly different $(\mathrm{F}=17.73, \mathrm{df}=9,38, p<0.0001)$ among plant parts, solvents of extraction and the environment from where the plants were collected (Table 2).

Table 2: Total variations on the effects of $C$. procera in inhibiting $E$. coli growth as described by the environment, plant parts, replication and solvent of extraction (model)

\begin{tabular}{llllll}
\hline \multicolumn{6}{l}{ Dependent variable: } \\
\hline Source & DF & Sum of squares & Means squares & F-values & Pr $>$ F \\
\hline Model & 9 & 28.499375 & 3.16659722 & 17.73 & $<.0001$ \\
Error & 38 & 6.78541667 & 0.1785636 & & \\
\hline
\end{tabular}

The factorial ANOVA revealed that significant variations were due to solvent of extraction ( $\mathrm{F} 45.52, \mathrm{p}<0.0001)$ and plant part (F 147.64, p < 0. 0001), while no significant variations on the ability of $C$. procera to inhibit E. coli growth were due to environment from where the plants were collected nor the replication (Table 3 ).

Table 3: Effects of extraction solvent, plant part environment and replication on the ability of $C$. procera in habiting E. coli growth

\begin{tabular}{llllll}
\hline Source Variation & Df & Type II SS & Mean square & F-value & Pr > F \\
\hline Environment & 1 & 0.125 & 0.125 & 0.74 & 0.3944 \\
Solvent & 1 & 7.7355556 & 7.7355556 & 45.52 & $<0.0001$ \\
Plant Part & 2 & 50.1811111 & 25.09055560 & 147.64 & $<0.0001$ \\
REP & 5 & 0.20277778 & 0.0405556 & 0.24 & 0.9639 \\
\hline
\end{tabular}

The effects of solvent of extraction indicated that the average diameter of growth inhibition zone was $2.88 \pm 0.47 \mathrm{~cm}$ and $2.1 \pm$ $1.08 \mathrm{~cm}$ for water and ethanol, respectively (Figure 2). When solvents of extractions were cross paired using t-test (paired two sample test for means) with $\mathrm{df}=29$, it was revealed that the actual t-value (5.9666) was larger in absolute value than the t-critical two-tail
(2.0452) and the two tail $p$-value (0.0000017) was less than the alpha $(0.05)$. This result indicated that water extracts were more effective in inhibiting $E$. coli growth compared to the ethanol extracts. 


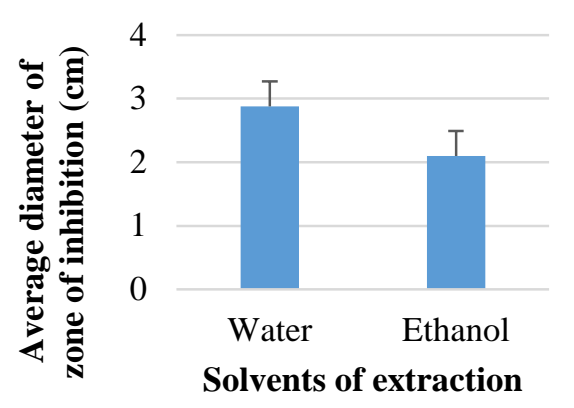

Figure 2: The average diameters of the E. coli growth inhibition zone due to solvent of extractions.

When the mean inhibition zones of extracts from different plant parts including positive control, the amoxicillin were analysed using single factor analysis of variance, very high statistically significant variations $(\mathrm{F}=51.98, \mathrm{df}$ $=3,74, p<0.0001)$ was observed. TukeyKramer test (post hoc test) after a one-way ANOVA using Microsoft excel (Table 4) revealed significant variations when amoxicillin, roots and latex were compared against leaves. However, no significant variation was observed between amoxicillin and roots, amoxicillin and latex and root and latex. This implies that amoxicillin, root and latex with inhibition zones of $3.558 \mathrm{~cm}, 3.087$ and $3.058 \mathrm{~cm}$, respectively had equal effects in inhibiting bacteria growth, and leaves comparatively had the lowest bacterial growth inhibitory effect.

Table 4: Effects of plant parts extracts of C. procera on inhibition of bacterial growth

\begin{tabular}{llllllll}
\hline & $\begin{array}{l}\text { Mean } \\
\text { Diff. }\end{array}$ & $\mathrm{n}(\mathrm{Gp} .1)$ & $\mathrm{n}(\mathrm{Gp} .2)$ & $\mathrm{SE}$ & $\begin{array}{l}\mathrm{q} \\
\text { (Calculated) }\end{array}$ & $\begin{array}{l}\mathrm{q} \\
\text { (Critical) }\end{array}$ & Conclusion \\
\hline Root -Latex & 0.029 & 24 & 12 & 0.1305 & 0.223 & 3.737 & $\mathrm{P}>0.05$ \\
Latex-Leaves & 1.450 & 12 & 24 & 0.1305 & 11.106 & 3.737 & $\mathrm{P}<0.05$ \\
$\begin{array}{l}\text { Amoxicillin- } \\
\text { Leaves }\end{array}$ & 1.950 & 12 & 24 & 0.1305 & 14.936 & 3.737 & $\mathrm{P}<0.05$ \\
$\begin{array}{l}\text { Amoxicillin- } \\
\text { Root }\end{array}$ & 0.470 & 12 & 24 & 0.1305 & 3.606 & 3.737 & $\mathrm{P}>0.05$ \\
$\begin{array}{l}\text { Amoxicillin- } \\
\text { Latex }\end{array}$ & 0.500 & 12 & 12 & 0.1507 & 3.316 & 3.737 & $\mathrm{P}>0.05$ \\
Root-Leaves & 1.479 & 24 & 24 & 0.1065 & 13.876 & 3.737 & $\mathrm{P}<0.05$ \\
\hline
\end{tabular}

\section{Discussion}

C. procera both ethanolic and aqueous extracts were effective against the growth of $E$. coli. The diameter of the inhibition zone varied depending on the plant parts and the solvent of extraction. According to Chung et al. (2004) the strength of the inhibitory activity are classified as strong if the diameter of inhibition zone is more than $2 \mathrm{~cm}$, and weak if the diameters of inhibition zone is less than 0.95 $\mathrm{cm}$. According to British Society for Antimicrobial Chemotherapy (BSAC), amoxicillin was regarded as effective against bacteria when the diameter for the zone of inhibition was greater than $2 \mathrm{~cm}$ (Andrew 2009). Therefore, C. procera root and latex extract had strong antibiotic activity against $E$. coli. It was further revealed that the inhibitory effects of roots and latex were not statistically significantly different from amoxicillin, implying that the roots and latex extracts may be used for the development of novel antibiotics. This is in agreement with Gordaliz (2009) who reported that approximately $80 \%$ of antimicrobial, cardiovascular, immunosuppressive, and anticancer drugs are of plant origins. When solvent of extraction was cross paired, results indicated that water extracts had significantly $(p<0.0001)$ higher zone of inhibition than ethanol extracts. Similar results have been reported by Somchit et al. (2003). This suggested that biologically active 
ingredients, were predominantly water soluble compounds such as anthocyanin, tannins, saponins terpenoids, polyphenols and lectins, but also polyacetylene, flavonols, steroids and alkaloids which are ethanol soluble compounds (Tiwari et al. 2011) were present. This would further suggest that the plant extracts could also act as antioxidants or free radical scavengers since flavonoids and tannins are antioxidant phenolic compounds (Ayoola et al. 2008), but also as insecticidal or phytoestrogenic because of naringenin or daidzein, respectively (Hussein and El-Anssary 2019). In contrary to our findings, when Bacon et al. (2017) cross paired solvents to extract antibacterial compounds in jalapeño peppers, it was revealed that methanoic extract followed by ethanolic extract had greater diameters of zones of inhibition than water extracts, while Akinyemi et al. (2006) found that both water and ethanol extracts of the three medicinal plants (Trema guineensis, Acalypha wilkesiana and Phyllanthus discoideus) were equally active against the three food borne pathogens. Thus solvent of extraction will depend on the nature of the active ingredients that is effective against a particular strain of microbe. Yuan et al. (2020) reported that ecological factors such as relative humidity, temperature, soil total phosphorus, soil $\mathrm{pH}$ and sunshine duration affected alkaloids and total flavonoids concentrations in D. officinale. To investigate whether environmental factors had significant effects on the $E$. coli growth inhibition, $C$. procera were collected from KahamaShinyanga, Lake Zone and from Dar es Salaam coastal lowland. The results obtained indicated no significant variations in diameters of the zones of inhibition between extracts obtained from Kahama and those obtained from Dar es Salaam. This preliminarily suggested that climatic factors, geographical factors or soil factors did not affect $C$. procera antibacterial activity. Thus $C$. procera collected from any environment within Tanzania might have sufficient medicinal values. However, more data are needed to draw the final conclusions.

\section{Conclusion}

The results on the ability of $C$. procera extracts to inhibit $E$. coli were sufficiently positive to encourage further investigations on the plant; biological activities on other microbes, phytochemical compositions, conservational status and the influence of climatic, geographical and soil factors. The results further provided a scientific basis for traditional uses of $C$. procera for medicinal purposes as for today more than 35,000 medicinal plant species are traditionally used for treatments and management of diseases by different cultural groups in the world. Moreover, the study showed that $C$. procera medicinal values did not change with the locations from where the plant parts were collected. Thus $C$. procera collected from any environment within the Tanzania might have significant medicinal values.

\section{Acknowledgement}

The Higher Education Students' Loans Board (HESLB) is highly acknowledged

for extending loan to Baluhya Marco, a BSc. in Botanical Science student. The acknowledgment is further extended to Charles Kweyunga the Chief Technician at the Department of Botany who assisted in the data collection and to the Department of Molecular Biology and Biotechnology of the University of Dar es Salaam that provided the pure strains of E. coli.

\section{References}

Akinyemi KO, Oluwa OK and Omomigbehin EO 2006 Antimicrobial activity of crude extracts of three medicinal plants used in south-west Nigerian folk medicine on some food borne bacterial pathogens. Afr. J. Trad. Complement. Altern. Med. 3(4): 1322.

Andrew JM 2009 BSAC standardized disc susceptibility testing method (version 8). $J$. Antimicrob. Chemother. 64: 454- 489.

Ayoola GA, Coker HAB, Adesegun SA, Adepoju-Bello AA, Obaweya K, Ezennia EC and Atangbayila TO 2008 
Baluhya and Joseph - Bacterial growth inhibitory effects of Calotropis procera's latex ...

Phytochemical screening and antioxidant activities of some selected medicinal plants used for malaria therapy in Southwestern Nigeria. Trop. J. Pharm. Res. 7(3): 10191024.

Bacon K, Boyer R, Denbow C, O'Keefe S, Neilson A and Williams R 2017 Evaluation of different solvents to extract antibacterial compounds from jalapeño peppers. Food Sci. Nutr. 5(3): 497-503.

Chung PY, Chung LY Ngeow YF, Goh SH and Imiyabir Z 2004 Antimicrobial Activities of Malaysian Plant Species. Pharm. Biol. 42: 292-300

Gordaliza M 2009 Terpenyl-purines from the sea. Marine Drugs 7(4): 833-849.

Heuzé V, Tran G, Baumont R and Bastianelli D 2016 Calotropis (Calotropis procera). Feedipedia, a programme by INRAE, CIRAD, AFZ and FAO. Accessed on 15/12/ 2020, available at https://www.feedipedia.org/node/588

Hussein RA and El-Anssary AA 2019 Plants secondary metabolites: the key drivers of the pharmacological actions of medicinal plants. Herbal Med. 1: 13.

Johan BP, Kristiansson E and Larsson DGJ 2018 Environmental factors influencing the development and spread of antibiotic resistance. FEMS Microbiol. Rev. 42 (1): fux053, https://doi.org/10.1093/femsre/fux053

Kumar G, Karthik L and Rao KVB 2010 Antibacterial activity of aqueous extracts of Calotripis gigantean leaves-an invitro study. Int. J. Pharm. Sci. Rev. Res. 4(2): 141-144.

Kuta FA 2008 Antifungal effect of calotropis procera stem on Epidermophyton flocosum. Afr. J. Biotechnol. 7(13): 2116-2118

Mensah MLK, Gustav K, Arnold DF, Caleb F, Alexander KA and Rita AD 2019 Toxicity and safety implications of herbal medicines used in Africa, herbal medicine. Intech. Open. DOI: 10.5772/intechopen.72437.

\section{Available}

from:

https://www.intechopen.com/books/herbalmedicine/toxicity-and-safety-implicationsof-herbal-medicines-used-in-africa

Miyata T 2007 Pharmacological basis of traditional medicines and health supplements as curatives. J. Pharmacol. Sci. 103(2): 127-131.

Morsy N, Al Sherif EA and Abdel-Rassol T 2016 Phytochemical analysis of Calotropis procera with antimicrobial activity investigation. Main Group Chem. 15(3): 267-273.

Oudhia P 2001 Calotropis gigantea; Useful weed. Society for Parthenium Management (SOPAM) 28-A, Geeta Nagar, Raipur 492001 India. Available from https://hort.purdue.edu/newcrop/CropFactS heets/calotropis.html. Accessed on 20/7/2020.

Somchit MN, Reezal I, Elysha Nur I and Mutalib AR 2003 In vitro antimicrobial activity of ethanol and water extracts of Cassia alata. J. Ethnopharmacol 84(1): 14.

Tiwari P, Kumar B, Kaur M, Kaur G and Kaur H 2011 Phytochemical screening and extraction: a review. Int. Pharmacetica Sci. 1(1): 98-106.

Varahalarao V and Chandrashekar NK 2010 In vitro bioactivity of Indian medicinal plant Calotropis procera (Ait). J. Global Pharm. Technol. 2(2): 43-45.

WHO 2020 Antibiotic resistance. Available at https://www.who.int/news-room/factsheets/detail/antibiotic-resistance Accessed on $15 / 12 / 2020$.

Yuan Y, Tang X, Jia Z, Li C, Ma J and Zhang J 2020 The effects of ecological factors on the main medicinal components of Dendrobium officinale under different cultivation modes Forests 11(1): 94; doi:10.3390/f11010094. 